\title{
Autosomal recessive spino-olivo-cerebellar degeneration without ataxia
}

\author{
A STAAL, ${ }^{*}$ SZ STEFANKO, † FGI JENNEKENS, $\ddagger$ LH PENNING DE VRIES-BOS, ${ }^{*} \mathrm{~J}$ VAN \\ GIJN*
}

From the Department of Neurology* and Pathology $†$ University Hospital Rotterdam (Dijkzigt), Rotterdam, and the Department of Neurology $\ddagger$ University Hospital Utrecht, Utrecht, The Netherlands

SUMMARY Five adult siblings from a sibship of ten suffering from an external ophthalmoplegia with a spastic paraplegia are reported. In addition, optic nerve atrophy was present in three of the patients and dementia in two; extrapyramidal signs and cerebellar ataxia were found only in one patient. Contrary to earlier studies of patients with comparable neurological signs the pattern of inheritance was autosomal recessive. Neuropathological investigation of the index case, who had never shown ataxia, nevertheless showed demyelination of the spinocerebellar and the olivocerebellar pathways, and also a severe loss of Purkinje cells, of cells in Clarke's column and in the inferior olives. The dentate nucleus was severely gliotic but showed no cell loss. Earlier neuropathological investigations of this disorder, but with an autosomal dominant heredity, were incomplete. It is concluded that the five siblings of this family have a unique autosomal recessive disorder, which should be considered a distinct entity.

An inherited syndrome with external ophthalmoplegia, pyramidal signs in the legs and extrapyramidal features has been described in four pedigrees. ${ }^{1-4}$ This disorder began in adult life with slowly progressive difficulties of gait. In several cases ataxia or optic nerve atrophy also was present. The inheritance in the reported pedigrees was autosomal dominant. Postmortem studies are confined to two cases. ${ }^{34}$ Unfortunately, in both the brainstem and the basal ganglia were only partially available for examination.

Our report concerns five siblings with ophthalmoplegia and spastic pareplegia, from a Dutch sibship of ten. The pattern of inheritance was most probably autosomal recessive. In three patients there also was optic nerve atrophy, dementia occurred in two, once together with extrapyramidal signs. Only one patient also showed ataxia. Neuropathological examination of our index case, who had no ataxia, nevertheless showed a gliotic dentate nucleus with a severe loss of cells in the cerebellar cortex, in the

Address for reprint requests: A Staal, University Hospital Rotterdam (Dijkzigt), 40 Dr. Molewaterplein, 3015 GD Rotterdam, The Netherlands.

Received 27 October 1982 and in revised form 20 February 1983. Accepted 12 March 1983 inferior olives and in Clarke's column, and also demyelination of the spinocerebellar and the olivocerebellar connections.

\section{Case reports}

The ophthalmological findings in our five patients are summarized in the table, and the pedigree is given in fig 1 . As far as could be ascertained, the parents were not consanguineous and had never shown any disturbance of mentation, vision or gait. The father died from myocardial infarction at the age of 52 years and the mother died of an unknown acute disease at the age of 84 . Between 1966 and 1977 we also examined all the living siblings of the patients, and some of their children; all of them were normal. It is improbable that definite symptoms in the other members of the family would not have been reported to us. Only the affected members will be described; three of these were seen several times.

Except for case III, who died before the time of our study, all siblings were known to have diabetes; it remained uncertain how many neurologically normal members of the family also had diabetes. In the other four patients the following laboratory studies were either normal or negative, apart from a raised blood sugar: urinalysis, haemoglobin and packed cell volume, ESR, blood morphology, liver and thyroid function tests, urea, creatinine, serum protein electrophoresis, CK activity, serum electrolytes, minerals, cholesterol and lipids, tests for syphilis in blood and cerebrospinal fluid, cell count, 


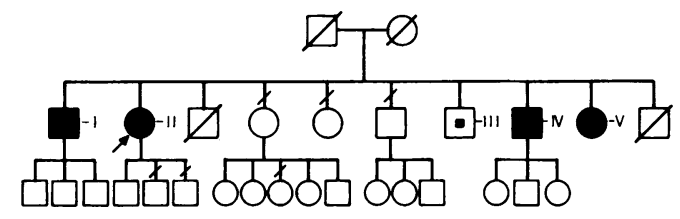

- II Index case

- III Reported ashaving had a spastic paraplegia of adult onset. not personally examined

Patients personally examined

古光

Normal persons. personally examined

OReported as not affected, not personally examined

$\triangle \varnothing$ Reported as not affected, died before the time of our study

Fig 1 Pedigree

glucose and protein in the cerebrospinal fluid, ECG, and radiographs of skull and thorax. Computed tomography of the brain and the orbits was normal in cases I, II and V, and was not performed in patient IV. In particular, the cisterns around the pons or the midbrain were not enlarged and there was no atrophy of the cerebellum.

\section{Case I, male born in 1906}

The first symptom in this patient was poor vision from the time he attended primary school. In 1958 he began to have low-back pain and difficulties in walking. From that time onwards his gait slowly deteriorated. In 1967 a neurologist noted "weakness" in the left eye on lateral gaze, bilateral optic nerve atrophy and a spastic gait. When we saw this then 71 -year-old man in 1977 , he was moderately disabled but still fully independent. He complained of bad vision, difficulty in walking and slight numbness in his legs. He did not take any drugs other than for diabetes, and he denied the use of alcohol. General physical examination was unremarkable except for a severe hypertension of 180/130 $\mathrm{mm} \mathrm{Hg}$. He was alert and formal psychological testing showed normal cognition. For the ophthalmological findings we refer to the table. Speech, swallowing, tongue movements and the jaw jerk were normal. In his limbs we saw neither atrophy nor fasciculations. Co-ordination, strength and tone of his arms were normal, but there was hyperreflexia. Vibration sense in the arms was impaired from the shoulder downwards. In the legs we found slight (MRC grade 4) weakness of the flexor muscles, and hyperreflexia with extensor plantar responses. Touch, pain and vibration sense were diminished below the hips. The muscle tone in the legs was only slightly increased as assessed from passive manipulation. His gait, however, was strikingly spastic and slow but without ataxia. He could not walk on his heels. The Romberg test was normal.

\section{Case II, female born in 1907 (index case)}

Her complaints began in 1947 with a shuffing gait and many falls. Save for her diabetes, which was diagnosed in 1951 in another hospital, she took no drugs nor alcohol. On examination in 1969 she had a normal vision and normal fundi. There was a gaze paralysis in all directions, with a normal doll's eye phenomenon. In addition to her spastic gait there was general hypertonia with very brisk tendon jerks in the legs, and bilateral extensor plantar responses. She was able to walk unaided, although with difficulty. On repeated examinations until her death in 1980 ataxia was never found. Formal testing in 1972 showed an IQ of 94 with a bad memory score, probably indicating early dementia. Her mental and motor condition slowly deteriorated. In 1976 she became bed-ridden. Admission in 1977 showed a demented woman with a mask-like face, a severe pseudobulbar dysarthria, and repeated periods of involuntary crying. The jaw jerk was very brisk and the snout reflex and the corneo-mandibular reflexes were positive. For the ophthalmological findings refer to the table. All limbs were strongly hypertonic with cogwheel rigidity and hyperreflexia without atrophy or fasciculations. Again ataxia was not present. Periodically there was a coarse tremor of hands and feet at rest. The arms showed normal strength and co-ordination. Muscle power was decreased in the legs, especially in the flexor muscles (MRC grade $2-3$ ), and the plantar responses were extensor. Only the sensation for pain could be tested, which seemed to be grossly intact. The electroencephalogram showed severe and diffuse, but non-specific abnormalities. Electromyography of several hand and leg muscles showed no signs of denervation. Motor conduction velocities and distal motor latencies were normal in the posterior tibial, the peroneal and the median nerve on the right side, and the latency of the right Hoffman reflex was also normal. A biopsy of the left quadriceps muscle showed morphological and histochemical signs of denervation atrophy. After her stay in our department she was transferred to a home for the severely disabled. In the last three years of her life we found no new neurological signs, although detailed examinations were hampered by the patient's spasticity and dementia. In 1980 she died of bronchopneumonia.

\section{Case III, male born in 1912}

This patient could not be examined because he committed suicide in 1966. According to his family he had for many years suffered from a progressively stiff gait. His family physician, who had known him for about ten years, informed us that he had definitely shown a spastic gait and hyperreflexia of the legs, without ataxia. This opinion was confirmed by the medical records of our hospital.

\section{Case IV, male born in 1916}

This patient told us he had difficulty in keeping his balance since about his 21 st year. At the age of thirty-five he began to have low-back pain, weakness in his left leg, and urinary frequency. Since 1972 his vision had been deteriorating. Except for antidiabetic drugs, he did not take medication or alcohol. Neurological examination in another university hospital at the age of 53 showed a visual acuity in the left eye of $4 / 16$, in the right eye of $4 / 9$. The right eye did not adduct completely on leftward gaze and on convergence. There was a spastic paraparesis with hyperreflexia and extensor plantar responses. Co-ordination and sensation were intact at that time. We examined the patient three times in 1977, when he was 61 years old. He was still able to get around, but was now complaining of falling backwards and of having pins and needles in hands and feet. On 
examination he was not demented, had no dysarthria, and showed a normal jaw jerk. For the ophthalmological findings we refer to the table. The finger-to-nose test showed bilaterally an intention tremor and his arm reflexes were brisk. The legs were hypertonic and showed weakness predominantly of the flexor muscles with hyperreflexia and extensor plantar responses. On both sides there was an ataxic heel-to-knee test, and he had a broad-based and spastic gait.

\section{Case $V$, female born in 1917}

In 1966 this patient was neurologically examined for the first time. She then complained of low-back pain and difficulties in walking since the age of 28 years. On examination there was a nystagmus on leftward gaze. The pursuit eye movements were saccadic but of full range. Her visual acuity was 0.8 in both eyes. The jaw jerk was absent. The arm reflexes were very brisk. Co-ordination and sensation in arms and legs were normal. Her legs were hypertonic, and there was a slight weakness (MRC grade 4) of the dorsiflexion of the foot. The tendon jerks were hyperactive and the plantar response on the left was extensor. Her gait was spastic. She was re-examined in 1977. Although her mental functions were not formally tested, we judged her to be slightly demented, and she showed involuntary crying. The general physical examination was normal. For the ophthalmological findings we refer to the table. Her speech was normal. The jaw jerk was now brisk and the corneomandibular reflex was bilaterally positive. There was no axial rigidity. The tone and muscle power of the arms were normal, as were co-ordination and sensation. The tendon jerks were abnormally brisk in all limbs and her legs were hypertonic with "pyramidal" weakness (MRC grade 4) and bilateral extensor plantar responses. Her gait was spastic, but co-ordination and sensation in the legs were normal. Electromyography and motor conduction velocities showed normal results.

\section{Postmortem examination of Case II}

Bilateral bronchopneumonia was considered the cause of death. Apart from this, general autopsy of this emaciated woman gave no relevant information. The brain, cerebel-

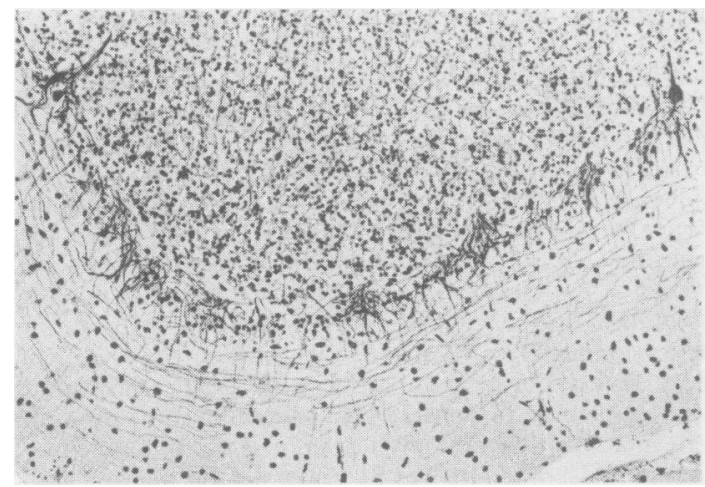

Fig 2 Cerebellar cortex. Severe loss of Purkinje cells and empty-basket formations. In the upper right corner-a torpedo. Bielschowsky stain. $\times 380$ lum, brainstem and spinal cord were normal on inspection. The cerebral ventricles were not enlarged and the brain weight was $980 \mathrm{~g}$. Microscopical study of the cerebral cortex and white matter, the fornices and the mamillary bodies were normal. Hardly any senile plaques and no neurofibrillar degeneration were found. The cerebellum showed a severe loss of Purkinje cells, together with numerous empty-basket formations, "torpedoes" and local swellings of dendrites with proliferation of the Bergmann's glia (fig 2). In the dentate nucleus there seemed to be no cell loss, but on Holzer staining there was a severe gliosis (fig 3). In the medulla both inferior olives showed a severe cell loss and were strongly gliotic (fig 4). There was demyelination and gliosis in the restiform bodies and in the olivo-cerebellar connections. Only slight demyelination was present in the brachium pontis and in the transverse fibres of the pons. The nuclei of the pons were normal for the greater part. In the nerve cells of the hypoglossal and

Fig 3 Gliosis of the dentate nucleus. Holzer stain.

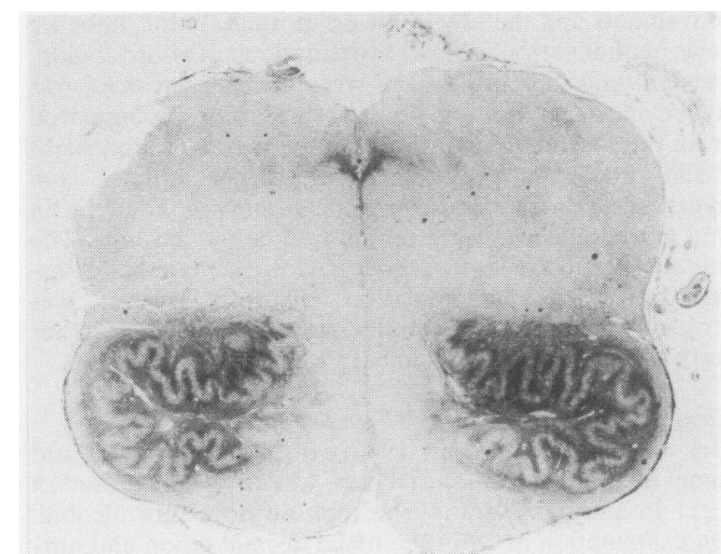

Fig 4 Severe gliosis of the inferior olives. Holzer stain. 
Table Neuro-ophthalmological signs in cases I, II, IV and V as found in 1977; case III could not be examined

\begin{tabular}{|c|c|c|c|c|c|c|}
\hline Case & $\begin{array}{l}\text { Vision and } \\
\text { Fields }\end{array}$ & Fundi & Pupils & Oculomotor signs & $\begin{array}{l}\text { Visually evoked } \\
\text { cortical potentials }\end{array}$ & Electroretinogram \\
\hline I & $\begin{array}{l}2 / 60 \\
1 / 60 \text { central } \\
\text { scotomas }\end{array}$ & atrophic & normal & $\begin{array}{l}\text {-retraction of upper eyelids } \\
\text { - external ophthalmoplegia (voluntary gaze) } \\
\text { - doll's eye phenomenon } \\
\text {-OKN: severely impaired response on ENG }\end{array}$ & absent & normal \\
\hline $\begin{array}{l}\text { II } \\
\text { (index case) }\end{array}$ & \pm normal & normal & normal & $\begin{array}{l}\text {-retraction of upper eyelids } \\
\text {-external ophthalmoplegia (voluntary gaze) } \\
\text {-doll's eye phenomenon: normal (1971) } \\
\text {-OKN: absent on ENG } \\
\text { - no reaction to caloric stimulation on ENG }\end{array}$ & $\begin{array}{l}\text {-left: slightly } \\
\text { decreased } \\
\text { - right: strongly } \\
\text { decreased }\end{array}$ & normal \\
\hline IV & $\begin{array}{l}5 / 10 \\
5 / 10\end{array}$ & $\begin{array}{l}\text { temporal } \\
\text { pallor }\end{array}$ & normal & $\begin{array}{l}\text {-retraction of upper eyelids } \\
\text { - external ophthalmoplegia (voluntary gaze) } \\
\text { - doll's eye phenomenon } \\
\text {-OKN: noormal on ENG } \\
\text { - caloric stimulation strongly asymmetrical on } \\
\text { ENG }\end{array}$ & not done & not done \\
\hline V & $\begin{array}{l}8 / 10 \\
8 / 10\end{array}$ & $\begin{array}{l}\text { temporal } \\
\text { pallor }\end{array}$ & normal & $\begin{array}{l}\text {-retraction of upper eyelids } \\
\text {-external ophthalmoplegia (voluntary gaze) } \\
\text {-doll's eye phenomenon } \\
\text {-OKN: normal on ENG } \\
\text { - no reaction to caloric stimulation on ENG }\end{array}$ & normal & not done \\
\hline
\end{tabular}

vagus nuclei there was granular and vacuolar degeneration. In the midbrain no abnormalities were found, in particular an extensive study of the oculomotor nuclei was entirely negative. In the substantia nigra and the nucleus coeruleus there was loss of pigmented cells, and free pigment was present outside the cells. One eye was available for examination, and on inspection it appeared to be normal. Microscopically there was a severe loss of ganglion cells in the temporal parts of the retina and also in the area of the macula. In the temporal part of the optic nerve, the axons and myelin sheaths were almost totally absent. In the central part of the optic nerve this fibre loss was somewhat less intense, and the nasal part of the optic nerve was normal. In the lumbar and cervical segments of the spinal cord we found a marked loss of the anterior motor horn cells. A number showed degeneration, and were surrounded by numerous thickened, contorted and fragmented nerve fibres. In Clarke's columns there were hardly any cells left. Both spino-cerebellar tracts and the medial parts of the posterior columns showed demyelination. In the pyramidal tracts the demyelination was only slight (fig 5). The pre-

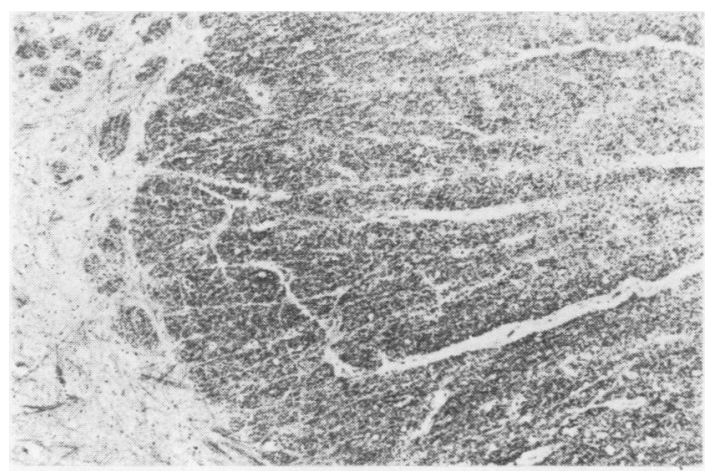

Fig 5 Thoracic medulla. Slight demyelination of the pyramidal tract (on the right side of the picture). Klüver Barrera stain. $\times 60$ and postganglionic autonomic nerve fibres, the sympathetic and the spinal ganglia and the cervical and the lumbosacral plexus were all normal. In the right median nerve at the level of the distal part of the forearm, the number of myelinated nerve fibres and the proportion of thickly and thinly myelinated fibres were estimated to be within the normal range. Electron microscopy revealed the presence of roundly shaped accumulations of glycogen-resembling granules within occasional axons.

\section{Discussion}

Our patients with hereditary spastic paraplegia, ophthalmoplegia and optic nerve atrophy resemble those originally described by Ferguson and Critchley ${ }^{1}$ in 1929 and to some extent also their descendants studied by Harding. ${ }^{5}$ However, the pattern of heredity in our family was most probably recessive and as such this disorder has not been described before. Contrary to Harding we did not find amyotrophy, fasciculations or areflexia. The wide range of the age of onset was comparable with Harding's findings, and the progression of the neurological deficit was also rather variable in the three patients we followed over a period of about ten years. Computed tomography of the brain, which is often diagnostic in olivo-(ponto)-cerebellar atrophy (OPCA), ${ }^{6}$ was not informative in the three patients in whom this study could be performed. These negative radiological findings were explained by the absence of gross atrophy of pons, midbrain and cerebellum at necropsy of our index case. This means that a normal CT scan does not rule out degenerative olivo-(ponto)-cerebellar disease.

The absence of ataxia in our index case was repeatedly confirmed over a period of eleven years, and in view of this the demyelination of the 
spinocerebellar tracts and of the olivo-cerebellar connections, the severe loss of nerve cells in Clarke's column, the inferior olives and the cerebellar cortex, and the gliosis within the dentate nucleus were surprising. Discrepancies also existed between the mildness of the changes in the lateral columns of the spinal cord and the severity of the spastic paraplegia, and between the normal cerebral hemispheres and the degree of dementia.

We cannot exclude that the severe abnormalities in the inferior olives and in the cerebellum had developed in the last years of her life when examination was hampered by her severe spasticity, but it is unknown for hereditary cerebellar ataxia to appear this late in the course of the disease. Unexpected pathological findings in hereditary neurological disease are certainly not a new observation, however, hereditary spino-olivo-cerebellar degeneration without ataxia is distinctly uncommon.

It is not known how severely the afferent and the efferent cerebellar connections or the cerebellum itself must be damaged before ataxia appears. On the basis of the incomplete investigation of the brainstem of the two cases which previously came to necropsy, Brown ${ }^{4}$ mentioned normal inferior olives, slight demyelination in the inferior cerebellar peduncles and a practically intact cerebellar cortex. In the dentate nucleus only mild neuronal degeneration was found, but the spino-cerebellar tracts showed definite demyelination and the neurons of Clarke's column were "quite sparse". Both these incompletely studied cases had shown ataxia during life, although the olivo-cerebellar connections were much less severely involved than in our case II, and although the inferior olives and the cerebellum were reported intact. It should be mentioned that the focal accumulations of glycogen granules within axons as observed in the median nerve of Case II, are a non-specific finding and have been reported in toxic neuropathy ${ }^{7}$ and in diabetic amyotrophy. ${ }^{8}$

From a purely clinical point of view, the signs in our index case mimick the end-stage of progressive supranuclear palsy, in particular the prominent ophthalmoplegia (most probably of the supranuclear type, because of the normal reflex eye movements, at least for some years, the retraction of the upper eyelids and the normal oculomotor nuclei on postmortem study). Additional similarities were the pyramidal signs, the axial rigidity and the dementia; only the atrophy of the optic nerves does not fit. However, progressive supranuclear palsy is still known as a non-hereditary disease, starting late in life and having a much shorter duration than the affliction of our index case. Among the various types of hereditary OPCA as distinguished by Konigsmark and Weiner' in their elaborate clinicopathological classification, only type II is composed of families with autosomal recessive inheritance. These type II patients often had early-onset cerebellar ataxia, but all lacked ophthalmoplegia and spastic paraplegia, and are therefore clearly different from the present family.

We conclude that the disorder found in the five siblings should be regarded as a hitherto unknown autosomal recessive entity.

The authors are most grateful to Dr WJ Meulenbelt-Groenendaal and Dr A Hijdra who helped to arrange the postmortem study, to $\mathrm{Dr}$ AGM van Vliet for electronystagmographic studies, to Dr K Mechelse for electromyographic studies, to Mrs J Doornbosch and Miss JM Magito for secretarial help, and to Miss D Kiers and Miss M van Batenburg for their histological assistance.

\section{References}

${ }^{1}$ Ferguson F, Critchley M. A clinical study of an heredofamilial disease resembling disseminated sclerosis. Brain 1929;52:203-25.

${ }^{2}$ Mahloudji M. Hereditary spastic ataxia simulating disseminated sclerosis. J Neurol Neurosurg Psychiatry 1963;26:511-13.

${ }^{3}$ Brown J, Coleman R. Hereditary spastic paraplegia with ocular and extra-pyramidal signs. Bull Los. Angeles Neurol Soc 1966;31:21-34.

${ }^{4}$ Brown JW. Hereditary spastic paraplegia with ocular and extra-pyramidal symptoms (Ferguson-Critchley Syndrome). In: Vinken PJ and Bruyn GW, eds. Handbook of Clinical Neurology, 1975;22 II,433-43.

${ }^{5}$ Harding AE. The clinical features and classification of the late onset autosomal dominant cerebellar ataxias. (A study of 11 families, including descendants of 'the Drew family of Walworth'). Brain 1982;105:1-28.

${ }^{6}$ Staal A, Stefanko SZ, Busch HFM, Jennekens FGI, Bruyn WC de. Autonomic nerve calcification and peripheral neuropathy in olivopontocerebellar Atrophy. J Neurol Sci 1981;51:383-94.

7 Vallet JM, Leboutet MJ, Loubet A, Piva C, Dumes M. N. Hexane and methylethyl-ketone induced polyneuropathy. Abnormal accumulation of glycogen in unmyelinated axons. Acta Neuropath 1981;55:275-9.

${ }^{8}$ Chokroverty S. Proximal nerve dysfunction in diabetic proximal amyotrophy. Electrophysiology and electron microscopy. Arch Neurol 1982;39:403-7.

${ }^{9}$ Konigsmark BW, Weiner LP. The olivopontocerebellar atrophies-A review Medicine (Baltimore) 1970;49:227-41. 